\title{
O SANGUE E A POLITICA: SOBRE A PRODUÇÃO DE FAMÍLIA NAS DISPUTAS ELEITORAIS NO SERTÃO DE PERNAMBUCO'
}

\section{BLOOD AND POLITICS: ABOUT THE PRODUCTION OF FAMILY IN ELECTORAL DISPUTES IN THE HINTERLANS OF PERNAMBUCO}

\author{
Jorge Luiz Mattar Villela* \\ Ana Claudia Duarte Rocha Marques**
}

\section{Introdução: o sertão e a política}

A polarização das disputas eleitorais entre dois "lados", "partidos" ou "facções" opositoras é comum em muitos municípios do interior brasileiro. A política de Jordânia se particulariza, no entanto, quando comparada a outros municípios da mesma meso e microrregião em que se situa ${ }^{2}$, no sertão pernambucano, porque ali essa polarização vigorou e persistiu em torno de dois lados oponentes identificados a duas das famílias tradicionais e antigas locais, os Santanas e os Gouveia. Após mais de três décadas de invencibilidade por parte dos primeiros, a oposição se reorganizou em torno de uma candidata à prefeitura não pertencente a nenhuma dessas ou qualquer outra das velhas famílias de Jordânia. Nessa mesma campanha de 2008, o candidato da situação faleceu a poucas semanas das eleições municipais. Vencidas as eleições, a prefei-

\footnotetext{
* Professor associado do Programa de Pós-Graduação em Antropologia Social da Universidade Federal de São Carlos (UFSCAR/São Carlos/SP/Brasil). Doutor pelo Programa de Pós-Graduação em Antropologia Social do Museu Nacional/Universidade Federal do Rio de Janeiro. villelajorge@gmail.com.

*** Professora associada do Departamento de Antropologia e do Programa de Pós-Graduação em Antropologia Social da Universidade de São Paulo (USP/São Paulo/ SP/Brasil). Doutora pelo Programa de PósGraduação em Antropologia Social do Museu Nacional/Universidade Federal do Rio de Janeiro. anaclaudiadrm@gmail.com.

1. Este artigo foi publicado originalmente em francês em Anthropologica, volume 58, n. 2. DOI 10.3138/Qnth.582.A04.FR. E aqui é reproduzido com a permissão da Editora da Universidade de Toronto - "Reprinted with permission from University of Toronto Press" (www.utpjournals.com). Agradecemos as leituras e comentários generosos de Hélène Clastres e Barbara Glowczevski, bem como de nossos avaliadores anônimos. 2. Os nomes dos municípios e dos personagens etnográficos deste texto foram inventados por um de nós (MARQUES, 2002).
} 
ta não se identificou como representante dos Gouveias, embora tenha encontrado apoio político entre eles. Desde então, os dois antigos lados opositores vêm se reconfigurando internamente no que se refere às alianças partidárias, nesse período que certamente é marcado pela força política inusitada exercida pelo Partido dos Trabalhadores na região. Os Santanas continuam nomeando um dos lados que disputam o governo municipal em Jordânia, mas seus opositores não são mais perfeitamente englobados como Gouveias ${ }^{3}$.

Nesse contexto, em algumas circunstâncias, "família" e "política" se tornam sinônimos e jamais se constituem como domínios autônomos de ideias ou de ações, conforme propomos explorar analiticamente, a partir de algumas noções locais de família e práticas a elas relacionadas. Com elas em mente nos debruçaremos, em um segundo momento, sobre três circunstâncias de crise que nos informam como o sangue e a política fazem-se e desfazem-se mutuamente, embaralham-se e confundem-se, pela ação dos atores.

Com nossa abordagem, visamos contribuir para um deslocamento dos debates sobre clientelismo no Brasil. Um dos fundamentos da democracia representativa é a depuração dos interesses familiares da vida política, embora esse ideal seja em toda parte frustrado. A análise da política e da família no sertão, enquanto concepções e práticas, remete a um campo de escolha e invenção, de agência individual e coletiva, para além da disputa pelo acesso, controle e distribuição de recursos escassos. Descrever analiticamente o misto família e política, geralmente considerado espúrio pelo pensamento político euro-americano, é uma forma de explicitar outras compreensões e práticas, em geral ocultas pelo 'semi ideal democrático' (VEYNE, 1983) que, no entanto, não costuma realizar-se em parte alguma ${ }^{4}$. A explicitação dos modos como os sertanejos vivem e fazem política tem por propósito e potencial liberá-los da noção de falta, intrínseca ao conceito de clientelismo, e o reconhecimento dos preceitos e pontos de vista que prevalecem na sua busca por produzir o próprio destino. Trata-se, como propôs Herzfeld (2005, p. 129), de "violar o monopólio das representações do Estado", na própria revelação do que se despreza como "fenômenos periféricos e triviais".

Jordânia situa-se cerca de $450 \mathrm{Km} \mathrm{a}$ oeste de Recife, a capital pernambucana. A população é de quase 32 mil habitantes, dos quais um terço habita na zona rural. As principais e mais antigas atividades econômicas dessa zona são a pecuária bovina e caprina e a agricultura, da qual os principais produtos são o milho, o feijão e a mandioca. Na cidade, para além do comércio, a principal fonte de emprego é a prefeitura,

3. Em outubro de 2016, o candidato dos Santanas (Orlando Santana - PRP) venceu as eleições para a prefeitura de Jordânia. Seus adversários se dividiram em duas outras chapas concorrentes. Após prolongada negociação, a então prefeita Cacau Medeiros e o deputado estadual Renan Gouveia concordaram em apoiar a candidatura de um primo de Renan, filiado ao PSD, e de uma sobrinha de Cacau, como prefeito e vice-prefeita respectivamente. Contudo, o então vice-prefeito (Arnô Gouveia - PT) manteve sua decisão de concorrer como titular de uma terceira chapa em disputa pela prefeitura municipal.

4. 0 uso de aspas simples neste artigo está reservado a termos do jargão antropológico e conceitos formulados pelos autores citados. As citações bibliográficas ou de nosso interlocutores, assim como as categorias e conceitos nativos são destacados por aspas duplas. 
seguida de postos de administração federal e estadual. Assim sendo, a política eleitoral, as eleições municipais mas também as nacionais e estaduais se fazem acontecimentos cruciais na vida de uma parte significativa da população. Os interesses econômicos impulsionam inegavelmente o engajamento dos eleitores no processo eleitoral. Nele, as adesões partidárias, os laços familiares e a administração pública também se misturam sem solução de continuidade. No entanto, as teorias que procuram explicar esse fenômeno através de conceitos como reciprocidade e monopólio de acesso e distribuição de recursos (WOLF, 1966; LANDÉ, 1977; EISENSTADT; RONIGER, 1984; GELLNER; WATERBURY, 1977) se apoiam sobre um caráter utilitário subjacente a cenários políticos desse tipo que, em nossa opinião, não esgotam a questão. Tampouco se esgota a noção de cultura política, que se teria consolidado no sertão em função de sua formação histórica.

Os historiadores brasileiros estão de acordo sobre o processo de ocupação territorial do sertão ${ }^{5}$ nordestino pelos agentes coloniais portugueses ter iniciado já no século XVI, paralelamente aos rumos do desenvolvimento de uma pecuária voltada para o abastecimento da população do litoral, onde as terras eram preferencialmente destinadas à monocultura da cana-de-açúcar (ABREU, 1982 [1907]; ANTONIL, 1982 [1711]). À medida que avançavam para o interior, um cenário muito distinto do litoral se descortinava. Na acepção atual, o sertão corresponde a uma vasta região de cerca de um milhão de $\mathrm{Km}^{2}$, de clima predominantemente semiárido, em boa parte recoberta por uma vegetação arbustiva e espinhosa - a caatinga - desprovida de fontes de água permanentes e periodicamente sujeita a secas. Essas condições físicas adequaram-se à pecuária extensiva, atividade econômica predominante por todo o período colonial, salvo nas pequenas manchas úmidas em que se praticava uma agricultura voltada para o consumo local (CORREIA DE ANDRADE, 1998 [1963]; MENEZES, 1937; PRADO Jr., 1980 [1945]).

Segundo Capistrano de Abreu (1982 [1907]), os currais se estabeleceram primeiro à beira dos rios e riachos, que serviam de rota de penetração no interior, e o cuidado da boiada empregava poucos braços. Os primeiros aglomerados populacionais do sertão se formaram em torno das capelas, aldeamentos missionários de catequização dos índios e de locais de feira, principalmente ao longo dos caminhos que serviam ao escoamento das boiadas (SANTOS, 1958; SAMPAIO, 2000; MARQUES, 2013b). Por muito tempo, a população sertaneja se manteve rarefeita, malgrado o alastramento rápido das fazendas, formadas a partir dos primeiros currais (PRADO Jr, 1980[1945]). De um modo geral, os fazendeiros eram arrendatários das terras que vieram a constituir seu patrimônio, transmitido às gerações subsequentes. Os herdeiros acrescentaram muitas vezes a esse legado as fazendas que eles mesmos formavam a partir de novo arren-

5. A origem do termo "sertão" é controversa, embora haja grande convergência sobre a referência a áreas não oficialmente ocupadas no interior do território brasileiro, longe do litoral. Segundo Sampaio (2000, p. 26), o termo aparece pela primeira vez em um dicionário, apócrifo, impresso em Lisboa, em 1485. Ali Certan é definido como "tudo que é apartado do mar e inserido entre as terras". Esse é o significado conferido ao termo quando se fala do processo de ocupação colonial do interior do Brasil. Em sentido mais estrito, sertão é uma das sub-regiões do Nordeste, com características físicas e climáticas que o distinguem da zona da mata, do agreste e meio-norte. 
damento. A forma do avanço das fazendas, o regime de herança e o casamento entre os filhos dos fazendeiros, que vieram se estabelecer no sertão, importaram na correlação entre parentesco e território, própria dessa formação social.

0 isolamento das longas distâncias e difíceis caminhos terá fortalecido o poder privado nas municipalidades do interior. As funções combinadas de administração, policiais e do judiciário, a cargo dos municípios, seriam efetivamente controladas pelos chefes locais emergentes entre os fazendeiros, os quais tomavam parte entre os "homens bons”, com prerrogativa de voto; entre eles ainda seriam eleitos os vereadores, os juizes ordinários e os demais oficiais das câmaras municipais (o procurador, o tesoureiro, o escrivão) durante o período colonial (LEAL, 1997 [1949]; FAORO, 1958). Apesar do processo de centralização e perda de autonomia municipal, que a historiografia dominante situa a partir de meados do século XVII e considera consagrado na independência, o poder dos potentados locais não terá sido de todo aniquilado, apenas condicionado à composição com as instâncias de governo a que o município estava submetido. Com a proclamação da república, o controle das prefeituras pelos chefes locais (os coronéis) passou a depender do acordo do governador da província, do qual eles se terão feito reféns políticos devendo-lhes provar fidelidade política através dos votos que lhe recrutavam entre correligionários e seus dependentes (parceiros, posseiros, agregados, moradores etc.) sobre os quais o direito ao sufrágio havia sido estendido. Esse esquema foi chamado "política dos governadores” (CARONE 1977). O coronelismo é um conceito difundido na historiografia política brasileira, anterior ao de patronagem (LEAL, 1997 [1949]; CARVALHO, 1997; GRAH-
AM, 1991). Nele, os coronéis são entendidos como brokers ou gatekeepers, funções indispensáveis para manter o sistema em vigor. Esse gênero de administração local se terá formado em articulação com as relações de parentesco. A historiografia brasileira distinguiu na família senhorial ou patriarcal o modelo analítico dos vínculos supralocais, necessários não só à defesa contra inimigos comuns, mas também à vida pública (OLIVEIRA VIANNA, 1987 [1949]; PEREIRA DE QUEIROZ, 1976; LEWIN, 1993). No entanto, nós sugerimos que a família é também força de contraposição à tendência monopolista do poder do coronel (VILLELA, 2004). Atualmente, o sistema político se funda sobre o multipartidarismo, mas apesar das mudanças de regimes no decorrer da história, os dados que extraímos de pesquisa de campo e de arquivos nos encorajam a analisar os modos como a família e a política partidária se misturam hoje, e também a cogitar (embora este último não seja nosso objetivo aqui) linhas de continuidade com regimes do passado (VILLELA, 2004).

A análise da combinação entre família e política se impôs a nós pelos nossos materiais de campo, por um lado, enquanto por outro encontrou ressonâncias na tradição do pensamento político brasileiro. Mas a fonte de inspiração para o desenvolvimento de nossas reflexões, nós a encontramos no NuAP (Núcleo de Antropologia da Política). A partir de meados dos anos 1990, o $\mathrm{NuAP}$ estimulou pesquisas que estendessem conceitos e métodos antropológicos ao estudo da democracia (PALMEIRA; HEREDIA, 1994; GOLDMAN; PALMEIRA, 1996; BEZERRA, 2004; VILLELA, 2008). Antecipando, em mais de uma década, antropólogos britânicos (CANDEA, 2011; SPENCER, 2007; CURTIS, 2012), os antropólogos brasileiros pretenderam privilegiar e levar a sério con- 
cepções nativas de política. Nossa disposição de levar adiante essa proposta, nos conduziu a deixar em suspenso as teses dominantes sobre as engrenagens políticas dos rincões brasileiros e a observarmos e ouvirmos atentamente o que podíamos ver e o que nos diziam os sertanejos a esse respeito. E assim, progressivamente apreendemos quanto $\mathrm{e}$ como família é parte da política.

A exemplo do que acontece com a política, o estudo do parentesco na antropologia procura evitar assumi-lo como um domínio autônomo. As relações de parentesco desempenham um papel fundamental nessa socialidade que procuramos descrever, precisamente porque elas se redefinem sem cessar em um jogo social em que variáveis de ordens diversas intervêm. Aqui se trata de demonstrar que família e política se fazem e desfazem uma à outra e que família não é algo dado, mas algo que se aprende e que se produz. Ela é um assunto de pedagogia e de uma seleção que depende de vários critérios, entre eles a política, não o único, mas um dos mais importantes.

\section{Densidade e fluidez}

A exemplo de inúmeras localidades no interior do Brasil, os sertanejos declaram amiúde que eles são ligados à maioria de seus conterrâneos por laços de parentesco. "Aqui é tudo braiado", eles dizem, "todo mundo é parente". Por um lado, essa constatação alude a uma concepção de um estoque de parentesco, amplo e indeterminado. Por outro, a fórmula exprime estratégias de inclusão e exclusão. Neste último registro, ela se aplica às familias ditas tradicionais, as mais antigas e prestigiosas do lugar, que subsumem ou deixam de lado outras, de chegada mais recente, de alguma forma marginais. Em referência às primeiras, os genealogistas de Jordânia elaboram grandes árvores genealógicas, que se confundem com a história local, especialmente a política. Como veremos, esses grandes mapas genealógicos não correspondem, contudo, ao estoque intensivo de parentesco. A árvore é uma superfície análoga às orelhas dos bodes, que levam as assinaturas pessoais e das casas de seus donos sobre isso nos debruçaremos adiante. Mas com pretensões totalizantes, onde se operam conexões e desconexões de indivíduos e coletividades, a árvore é também dispositivo narrativo que amplia e condensa pertencimentos e hierarquias, também presentes em outras metáforas vegetais de família, como "troncos" e "ramos". A política é um fator central na dinâmica de constituição e redefinição constante e circunstancial do que se considera família, ao mesmo tempo que se formula no mesmo processo.

"Mamãe nunca nos ensinou que nós éramos parentes", declarou uma amiga de Jordânia, a respeito de um "ramo" familiar local que, no entanto, tem o mesmo sobrenome dela. Os laços de parentesco que a ligam a esse "ramo" são facilmente detectados, basta remontarmos algumas poucas gerações genealógicas. Da mesma forma que o termo família pode ser estendido a pessoas não ligadas por parentesco ou afinidade nessa formação social, convém argumentar, no sentido oposto, que não são da família as pessoas não "reconhecidas" ou não "consideradas" como seus membros (MARCELIN, 1996), independentemente dos vínculos genealógicos que se saiba haver entre elas. Essa extensão ou restrição do termo são entendidas como metafóricas, para alguns antropólogos, ou como 'discurso de ocasião' (BOURDIEU, 1963). Na estreita fusão entre família e política que examinaremos aqui, contudo, o processo de familiarização e desfamiliarização (COMERFORD, 2003) é sempre assumido em sentido literal. 
Nossa abordagem implica na adoção de uma perspectiva processual (CARSTEN, 2000) e política da família, capaz de enriquecer e subverter o sentido da fórmula "o sangue é mais denso que a água”, utilizada por Schneider (1984, p.165) para explicitar os pressupostos que guiariam os estudos antropológicos do parentesco. Nossos dados de campo revertem a fórmula de Loizos (acerca dos cipriotas) segundo a qual "o sangue é mais denso que o alinhamento político” (1976, p. 78). Em Jordânia, como veremos ao longo deste artigo, a política tanto adensa quanto dissolve o sangue. Nossa análise descritiva desse processo começará pela apresentação de noções familiares que estruturam as concepções e práticas do parentesco em Jordânia.

\subsection{Noções e imagens da família}

Para os que vivem nas zonas rurais do município, a "casa" compreende a edificação de sua moradia, o terreno que abriga os recursos de subsistência dos seres humanos incluídos nesse nicho existencial, bem como todas as pessoas que o habitam, desde logo as que são ligadas por parentesco ou que são assim assimiladas. Quando nossos interlocutores utilizam expressões como "lá em casa” ou "nossa casa”, a noção adquire uma dimensão temporal. Como observou Segalen $(1981$; 1996), a variação na composição dos membros de um grupo doméstico, ao longo de seu desenvolvimento, desafia toda simplificação tipológica dessas unidades. Nós observamos, no entanto, que essas composições são, igualmente, sincrônicas. A casa pode se referir ao lugar onde os habitantes residem em um dado mo- mento, a um grupo de pessoas que viveram e cresceram sob um mesmo teto, notadamente uma "irmandade" com seus pais, ou ainda a todo um conjunto de descendentes desse grupo, mesmo que a maioria deles jamais tenha morado ali.

A polissemia do termo torna difícil toda identificação unívoca do sentido local da noção de casa aos conceitos antropológicos ligados a essa palavra. Diferentes aspectos dessas diversas acepções nos remetem ao 'grupo doméstico', assim como às dimensões de convivialidade que Marcelin (1996) e Carsten e Hugh-Jones (1995) acrescentam ao conceito de casa, a partir de suas revisões críticas das sociétés à maison de Lévi -Strauss (1984) ${ }^{6}$. Entre as grandes e antigas famílias do sertão, que se instalaram ali desde o século XVIII, algumas casas adquirem uma personalidade expressa pelo uso de nomes próprios. 0 Jericó, por exemplo, designa a casa e as terras em que se estabeleceu o casal João Regino e Maria Trindade. Ali eles criaram seus treze filhos, conviveram com parentes, moradores, vizinhos, visitantes, constituíram uma reputação entre todos eles. Os numerosos descendentes daquele casal são considerados “do Jericó”, independentemente de seus endereços residenciais ou de onde eles nasceram. Nesse sentido, a casa implica um segmento socioterritorial no seio do qual predomina um "sangue", ao qual são atribuídas qualidades determinadas. Trata-se do sentido mais amplo da categoria "casa”.

As casas são ligadas entre elas e constituem, nessas condições, uma 'configuração de casas' (MARCELIN, 1996), espacialmente contíguas (embora haja de costume uma boa distância entre elas, mesmo quando vizinhas) 
ou dispersas no interior e fora de uma região, nas zonas rurais e urbanas de um mesmo ou de municípios vizinhos, nas cidades de Pernambuco e alhures. Uma tal 'configuração de casas' pode fazer referência a uma localidade: Jericó, Jaburu, Açude Novo são casas da Fazenda Umbuzeiro, todas elas ligadas entre si por laços de parentesco e correspondentes a diferentes parcelas de um mesmo patrimônio original. As Fazendas são, assim, segmentos socioterritoriais englobando casas que os compõem. Trata-se de um nivel segmentar no seio do qual encontramos, no sertão de Pernambuco, uma das dimensões das relações familiares identifıcadas por Lévi-Strauss em seu conceito de 'casa'.

A noção de família implica igualmente a noção local de "linhagem", que designa o conjunto de descendentes de um, ou uma, ancestral ilustre no interior da fazenda ou na região. Ainda que enunciada bem mais raramente, a "linhagem" se presta especialmente à compreensão de uma forma de segmentação paralela à noção de família. No sertão de Pernambuco há o costume de transformar nomes pessoais ou sobrenomes de pessoas ilustres em uma sorte de subnomes familiares, por vezes incorporados aos registros oficiais. Assim nomeados, os descendentes de um chefe de família se reconhecem e são reconhecidos, distinguindo-se, dessa forma, como uma "linhagem". Os descendentes diretos do Major Clemente são conhecidos como Clementes. Esse dispositivo consuetudinário faz ou revela que o Major é, do ponto de vista de seus descendentes, um "tronco". Se a "Fazenda Umbuzeiro" é uma parcela de um patrimônio original cuja unidade persiste, não obstante a fragmentação contínua por herança e alienação, os Clementes são um segmento do nome Santana, ao lado de numerosos outros que constituem os Santana do Umbuzeiro. Também “os Flor” são assim conheci- dos por descenderem de Florência Felismina de Sá. Embora operando como tal, jamais ouvimos ela ser designada como "tronco", possivelmente por se tratar de uma mulher; contudo, a "irmandade" que gerou adquiriu grande fama pela tenacidade na perseguição a Lampião e seu nome distingue todo um "ramo" dos "Santana do Jericó", aparentado e ao mesmo tempo diferenciado dos Clementes e dos Santana da Umbuzeiro.

Nas famílias "antigas” do sertão, ao cabo de gerações sucessivas, alguns membros se tornam "troncos" a partir dos quais se formam novos "ramos”. Esse é um vocabulário de prestígio: aqueles que "são do tronco" são considerados "verdadeiros" Santanas, Garcias, Pereiras etc. Do ponto de vista genealógico, mas também político, a imagem de "troncos" e "ramos" pode ser interpretada de duas formas. De um "tronco" se desprendem vários "ramos”, ou então um "tronco" é o ponto de origem de um "ramo". Essa observação é correlata de outra: conforme o contexto, alguém será "tronco" ou "ramo", da mesma forma que a composição desses mesmos "troncos" e "ramos" varia em função das circunstâncias. A Fazenda Umbuzeiro é, ela mesma, um "tronco", formado pelo Major ou então por seu avô materno, que deixou em testamento a fazenda, parcela de seu patrimônio, a uma de suas filhas, de quem o primeiro foi o primogênito. Desse ponto de vista, Umbuzeiro é também um "ramo" destacado do "tronco" original, os Santanas. No interior dessa "fazenda", vários "ramos" se formaram, entre os quais alguns são particularmente antigos e outros são desdobramentos sucessivos e mais recentes daqueles sempre nomeados a partir dos nomes e sobrenomes introduzidos na família por casamento. Malgrado a maior estabilidade das divisões mais antigas, os pontos de onde surgem as ramificações e mesmo a confor- 
mação de "ramos" não são consensuais, e sua localização genealógica depende dos contextos nos quais o grupo que se pretende designar é pertinente. De certo ponto de vista, o processo de "ramificação" é também aquele que cria os "troncos": variáveis de poder e prestígio, temporais e morais intervêm aí. Mas esse processo não é algo que existe ou se apresenta por completo e acabado para que os antropólogos possam registrá -lo. Não se fala sempre das mesmas pessoas nem dos mesmos coletivos: em certa medida, "troncos" e "ramos" são construídos de forma ilocutória. Com efeito, a dinâmica das ramificações e dos entroncamentos reproduz as propriedades múltiplas e frequentemente paradoxais do "sangue", notadamente sua fluidez e sua personalidade, assim como sua capacidade de se manter pura e de se misturar a outros, ao mesmo tempo (CARSTEN, 2013). No sertão, o "sangue" é sempre ligado ao nome individual ou coletivo e é o meio pelo qual as famílias se circunscrevem ou se diferenciam, qualquer que seja a abrangência que confıramos à noção.

As "irmandades" constituem os grupos mais estreitamente ligados pelo "sangue", mas, em seu seio, as diferenciações individuais são significativas: um irmão exprime mais do que o outro, por sua aparência, sua atitude e seu temperamento, as características de um ancestral, porque nele, supõe-se, o "sangue" transmitido por seu pai ou mãe predomina. Os casamentos entre parentes por vezes muito próximos, mais frequentes no passado do que hoje em dia, contribuí- ram para a conformação de uma correspondência entre nome, território e reputação. Mas essa coesão é sujeita a divisões, as quais se explicam também pelo "sangue", uma vez que cada indivíduo é portador de uma combinação única de "sangue" ao mesmo tempo que é "do mesmo sangue" que todos os seus ancestrais e colaterais de qualquer grau, desde que se reconheça o parentesco, por linha feminina ou masculina (MARQUES, 2002).

Os processos de segmentação linhageira e territorial, de ramificação e entroncamento, de mistura e pureza de "sangue" são parcialmente coextensivos e podem ser observados na sinalética das orelhas dos bodes. A "assinatura" das orelhas pode ser entendida como uma expressão gráfica dessas dinâmicas, bem como os ferros de marcar os bois (BARROSO, 1956, p. 189). No caso dos caprinos, essa "assinatura" é realizada a cada ano sobre os cabritos do rebanho da "casa”, que nessa ocasião são repartidos entre seus membros. Marca indelével de pertencimento, a "assinatura” é composta de três signos. A orelha direita é reservada ao sinal da "fazenda”, presente em todos os animais que são criados aí. A orelha esquerda é dividida em dois: a parte superior porta o sinal da "casa" e a inferior é reservada à marca individual do proprietário do animal.

No curso das gerações, as "assinaturas" sofrem modificações que correspondem a processos de segmentação associados a outros processos, de natureza político-linhagei$\mathrm{ra}^{7}$. A "cruz", que há mais de um século foi o sinal pessoal do Major Clemente, usado na

7. Também os ferros dos bois sofrem essas modificações no curso das gerações. Sobre um padrão original, marca de uma "fazenda", as diferentes "casas" introduzem variações que as identificam como proprietárias da rês. Esse tipo de marcação seria muito mais eficaz, segundo nos explicou um vaqueiro do Umbuzeiro, do que as letras correspondendo a iniciais de nomes próprios, mais recentemente adotadas na marcação do gado. Um conjunto de signos derivados de um mesmo padrão original permite que um vaqueiro identifique com facilidade a região de onde terá partido uma rês tresmalhada, ainda que ele desconheça a que casa específica ela pertence. 
orelha esquerda de seus cabritos, hoje é marcada na orelha direita nos rebanhos de seus descendentes, de toda o Umbuzeiro. 0 sinal que no tempo dele era rasgado na orelha direita deixou de ser utilizado. Canzil, coice de porta, boca de lagarta, dente de mourão, dente descoberto, morsa, brinco, muitos são os recortes cuja combinação e distribuição nas duas orelhas identifica com precisão os donos da criação. Ao mesmo tempo, fixas e suscetíveis às transformações do tempo, que decorrem de combinações e separações, as “assinaturas” das orelhas revelam uma concepção genealógica que escapa aos diagramas de antropólogos e genealogistas (BOUQUET, 1996). Elas explicitam recortes e pertencimentos, cujas mudanças ao longo do tempo são registradas na memória dos criadores. Os genealogistas pretendem, ao contrário, produzir um registro cumulativo e abrangente, homogêneo e neutro.

No sertão de Pernambuco, a genealogia se divide em duas grandes significações e formas principais: primeiro, ela designa um estoque virtual, intensivo, pré-nominal de parentes (DELEUZE, 1988; DELEUZE; GUATTARI, 1972). Pura intensidade, ela carece de capacidade discursiva e descritiva de parentesco. Por natureza virtual, ela só se atualiza em fragmentos no cotidiano. A expressão local "destrinchar o parentesco" permite compreender o processo que consiste em transformar o confuso em analisado, o intensivo em extensivo. Essa virtualidade sustenta o próprio processo do "destrinchamento". A "assinatura" das orelhas, a enunciação de "troncos" e "ramos", a classificação de pessoas em "casas”, "fazendas" e "linhagens" são formas de atualização, no sentido extensivo atual de genealogia, que também se manifesta ou redunda em uma pedagogia do parentesco.

A segunda signifıcação da genealogia, enquanto atualidade, exige uma enunciação oral ou escrita. Os livros de genealogia que proliferam em Jordânia são a expressão extensiva de um estoque de filiação política. Eles não são o 'virtual-real' da genealogia. Antes, eles são uma atualização política desta última, que funcionam como um critério seletivo que distingue os parentes dos não parentes. 0 parentesco dito ou escrito, embora seja considerado como a genealogia em sua totalidade, recorta o contínuo genealógico virtual com o instrumento político da memória. Escrita, a genealogia confere prestígio e dignidade àqueles que ela inclui e provoca a revolta nos parentes que exclui.

Quando um relato genealógico pretende englobar a totalidade do estoque de parentesco ele é negligenciado e considerado uma tarefa inútil, porque ele contradiz as implicações políticas do memorialismo. A pretensão de atualizar completamente o virtual-real da genealogia é considerada um trabalho nobre e erudito, mas que carece de sentido. A noção de família, nos diferentes sentidos e formas de que se reveste, varia em função da vida cotidiana. Em sentido administrativo, partidário ou eleitoral, a política ocupa uma parte significativa da vida dos Jordanianos. A seguir, veremos como ela é capaz de fazer e desfazer família.

\section{Política e família}

A política eleitoral é um instrumento poderoso que permite fazer e desfazer família no sertão de Pernambuco e, de modo especial, em Jordânia. Trata-se mesmo de um dos critérios mais importantes de seleção e de atualização do estoque de parentesco. Da mesma forma que a propriedade móvel dos rebanhos e imóvel das fazendas, a política é algo que se herda e transmite e que, por vezes, pertence ao "sangue". 
Alguns autores, a despeito das diferenças de objetivos e do aporte teórico de seus trabalhos, assinalaram os esforços de purificação entre família e política ao longo dos quatro últimos séculos (FABIAN, 1983; DONZELOT, 1986; KUPER, 1988; HERZFELD, 1992; CARRIER, 1995; JULIEN, 2008). Em 1975, Foucault assinalava já um processo de destronamento das funções da soberania da família, transformando-a em meio de vigilância que permite a introdução das disciplinas no espaço doméstico. Segalen expõe a tentativa do Estado de produzir uma "família reduzida às funções menos importantes” (1996, p. 35), de que o efeito seria a celebração desta como grupo doméstico de consumo e de reprodução social, privado de atividades políticas nas quais anteriormente se engajava. 0 0cidente, como sugeriu Donzelot (1986, p. 47), desenraiza a família de suas conexões coletivas.

A cisão da família e da política criou um delito, o nepotismo. A separação entre os domínios familiar e político forneceu as condições necessárias à elaboração de escalas de perfeição, fundadas mais sobre ideais do que sobre a diversidade das práticas. Com efeito, conforme mostram certas etnografias, mesmo em países centrais, por assim dizer, os laços familiares continuam importando na aplicação da política parlamentar, partidária e eleitoral (ABÉLÈS, 1991; 2001). Não são a falta ou a incompreensão as responsáveis pela interpelação familiar na política e vice-versa. A família se imiscui na política da mesma maneira que diversos aspectos da vida política (sob a forma de campanhas de governos, por exemplo) pretendem intervir na vida familiar.

Em certos lugares do sertão, família e política tornam-se sinônimos em certas circunstâncias. Ao menos para uma parte significativa (senão em quantidade, em prestígio) das pessoas com quem convivemos, não existe família que não esteja associada à atividade política, ao passo que o êxito da candidatura de um indivíduo a um cargo eletivo depende da pertença a uma família e vice-versa. Da mesma forma que a sinalética das orelhas dos bodes e dos ferros dos bois demonstram a segmentação dos grupamentos chamados família, também ocorre com a política eleitoral, visto que esta é uma das formas mais poderosas de se fazer e desfazer família no sertão de Pernambuco e, sobretudo, no município de Jordânia. Eis o que nos ensinam situações como as que passaremos a relatar.

\subsection{Afiliação política e familiar}

Cerca de um ano após as eleições presidenciais de 2010, ouvíamos as queixas de um amigo e partilhávamos as suas angústias. Três anos antes, nas eleições municipais, ele era um dos protagonistas da campanha derrotada de sua coligação, da sua família política, e por isso tinha a expectativa de ser convidado a candidatar-se a vereador dali a quatro anos. Entre 2008 e 2012, ao longo das conformações de apoios e ofertas de recursos para as eleições gerais, a despeito de suas expectativas, fora posto às margens do processo. "Querem só que eu lhes sirva. Querem fazer política de sangue puro", disse-nos ele, amargo com seu próprio destino.

No sertão, "sangue" é prole, filiação, família, gente de alguém, de algum lugar, de alguma descendência. Ele faz perseverar, em continuidade, costumes, hábitos, comportamentos. 0 "sangue" é condutor. Ele faz com que alguém seja "manso" ou "brabo", "valente" ou "mole”. E conduz também a "política”. Há quem traga a "política no sangue”, como se diz frequentemente. De um homem de uma família "braba" (implicados aqui os 
princípios da territorialidade e da convivência), espera-se que reaja em consonância com o que várias gerações de sua família fizeram. Histórica e administrativamente, esses critérios serviram para selecionar os responsáveis pela manutenção da ordem e da paz nos sítios, quer dizer, na zona rural (VILLELA, 2004), bem como para recrutar os combatentes em "brigas de família" (MARQUES, 2002; 2013). 0 “sangue” responde pelos traços de caráter, pela fisionomia, pelo andar, pelo humor de cada um. Cada um é, ao mesmo tempo, um indivíduo original e o resultado da mistura dos sangues materno e paterno. Veremos já, contudo, que o "sangue”, como aspecto ou expressão da família, tampouco é dado ou natural. Ele também é agente e paciente de seleção, pois não se herda as características transmitidas por ambos os pais na mesma proporção.

A "política de sangue puro", de acordo com nosso amigo, era a "política" que seus antigos correligionários pretendiam fazer ao excluir gente como ele do protagonismo das ações político-eleitorais, ao retirá-lo da lista dos parentes ligados a Pedro Marchante que, na década de 1910, havia tomado para a sua linhagem as rédeas da política do município. Visto de cima, como foi explicado anteriormente, Pedro Marchante é considerado um "tronco".

Segundo nosso amigo, o século XX em Jordânia fora marcado pelo que se chamou de "política de famílias". Desde 1913, os Gouveia, antigos protegidos dos Santana, conquistaram o peso político até então atribuído aos Garcia, estes últimos muito poderosos durante o Segundo Reinado (18401889). Naquele ano, os Gouveia disputaram com os Santana a prefeitura e a maioria na câmara dos vereadores. Desde então e até 1976 houve alguma alternância de vitórias e derrotas no poder municipal entre as duas "famílias". Entre 1976 e 2004, os Santana venceram todos os pleitos majoritários. Após tantas derrotas nas urnas, seus adversários terão investido em outra forma de fazer política, conhecida como "política de grupos”, isto é, um modo de afiliação partidária independente das relações familiares. No entanto, conforme nosso amigo nos permitiu compreender, da mesma maneira que a "política de família" forma grupos, a "política de grupos” não consegue se liberar do "sangue" e da "família". As duas opções na verdade coexistem e competem no seio de ambos os partidos ou lados em conflito.

0 "grupo" que seus antigos correligionários estavam formando naquele momento com vistas às eleições seguintes não era isento das influências do "sangue", mas o abastardava, por assim dizer, ao incluir pessoas não localizáveis na genealogia, ao mesmo tempo que cassava alguns parentes legítimos, a fim de concentrar o poder em uma só "linhagem". Por outro lado, nosso amigo sustentava que a ignorância genealógica dos selecionadores do "grupo" permitia exclusões e inclusões arbitrárias, exclusivamente fundadas na conveniência, na camaradagem, na subserviência e nos interesses financeiros da campanha eleitoral.

Mas sua requintada avaliação políticofamiliar não se esgota aqui, pois mostra bem as intrincadas conexões existentes quando se trata de "sangue" e de "política". Acionar a genealogia, em seu caso, permite que ele mesmo se situe na linha colateral de descendência de Pedro Marchante (que era irmão de sua bisavó paterna e dois trisavôs maternos). Ele mostra que a atualização da genealogia na "política”, embora real, é argumento de seleção, recorte, fragmento de um contínuo muito mais amplo e virtualmente ilimitado - porque externo à extensão. Ser ou não Marchante não é um 
dado, mas uma atualização de um parentesco possivel, posto que existe no estoque filiativo intensivo.

Em suas reflexões, nosso amigo retorna a dois aspectos da família mencionados anteriormente. Por um lado, reconhece-se um legítimo aspirante a esse novo "grupo" que se ergue, tanto por suas competências técnicas quanto pelo "sangue" que partilha com os Marchantes. Ele está apto a reclamar esse segundo critério em virtude da indeterminação da cadeia filiativa, que repousa sobre o princípio da filiação cognática. Ele dispõe das competências necessárias para procurar seus ancestrais no estoque virtual de parentesco para atualizá -lo, servindo-se para isso da genealogia e dos critérios de seleção política. Por outro lado, esse percurso genealógico seguido por ele precisa ser reconhecido e considerado pelos outros. Embora seu sobrenome não seja o mesmo dos captores do grupo político, ele alega a sua pertença à "família” baseado em argumentos irrefutáveis do ponto de vista da árvore genealógica. Argumento nada negligenciável em um lugar onde a genealogia é uma paixão e onde os seus guardiões são celebridades, onde se recorre aos livros publicados sobre a matéria, bem como ao site "Genealogia Pernambucana”, que dispõe de instrumento de busca que permite traçar todos os laços de parentesco entre dois indivíduos. No entanto, o reconhecimento que nosso amigo esperava de seu enunciado genealógico não se efetuou, porque não se fez acompanhar das práticas pedagógicas do parentesco. Os membros do "grupo" não aprenderam que ele era parte da "família". Tudo isso lhe parece, finalmente, uma articulação indevida do parentesco, que o desqualifica como meio seletivo de participação e exclusão. De todo modo, sua narrativa nos mostra uma tentativa de fazer família que esbarrou, nesse caso preciso, na política que desfamiliariza. Aqui, a política é mais densa que o sangue.

Reflexões, neste caso decorrente de uma crise, de uma derrota eleitoral, nunca são ingênuas. 0 parentesco é um tipo de relação política, repleta de intencionalidades. A neutralidade só se aplica ao virtual-real, jamais à genealogia árvore, mesmo quando se atualiza pela escrita. "Coisa sem futuro", fruto do ócio ou "coisa de gente besta", ela no entanto não é apenas exercício de erudição ou fonte de anedotário. Seus depositários parciais, os genealogistas, servem para alguma coisa. Pois eles dirimem dúvidas e "destrincham" o parentesco para além do conhecimento exigido pela vida cotidiana, intencional, cujo funcionamento pode exigir a reivindicação de certos laços de parentesco. 0 que nos leva ao segundo caso, o de um genealogista cujos conhecimentos, à primeira vista inúteis, foram mobilizados politicamente. Ao contrário deste primeiro amigo, que parte da política para analisar a genealogia (e retorna para a política), o casal de quem falaremos doravante parte do saber parentesco para o recorte da política.

\subsection{0 genealogista na política}

0 homem do casal em questão é um memorialista que aspira atingir a genealogia virtual, total e liberta dos recortes políticos, da pedagogia, do cotidiano. Seu trabalho é, portanto, infinito. Chamemo-lo Funes. Ele constrói laboriosamente uma árvore a partir de pesquisas que realiza em arquivos e de relatos que recolhe entre os que sabem mais do que ele, ou sobre vínculos de parentesco que ele desconhece, capazes de iluminar trechos e ramos até então sob a sombra. Ele e sua mulher, ambos primos 
entre si diversas vezes, pertencem por sobrenome e por reconhecimento à família Garcia, cuja origem se confunde com a ocupação colonial do território e cuja liderança política em Jordânia chega a termo na década de 1910. Desde há muitos anos, como seus avós, pais, tios e primos, o casal "vota com" a família política que assumiu o lugar da sua no protagonismo político do município, os Gouveia.

Nosso casal de amigos alegam que, ao contrário de grande parte de seus conterrâneos, eles não votam por precisarem da política, em relação à qual eles se consideram autônomos. Eles fazem parte de uma classe de sertanejos que rejeita a política como meio de angariar recursos materiais; que consideram humilhante, desonesto ou aviltante solicitarem recursos em troca de seus votos. Muito tradicionalista, no entanto, Funes acha que votar é um direito e um dever, sacralizado no desempenho de uma vida cidadã. Muitos sertanejos comungam dessa avaliação da política eleitoral e da democracia representativa.

Para nosso casal, a escolha do voto não se resume, contudo, a esse aspecto. Eles votam "por consideração", porque muitos dos candidatos são parentes, embora vários deles, ressente-se Funes, recusem-se a registrar os filhos com seu sobrenome, preferindo os dos politicamente prestigiados ou, quando os registram com o sobrenome, não ensinam a eles os parentes da família do casal, porque parentesco, não custa insistir, se aprende e se ensina, e portanto é efeito de uma pedagogia cotidiana.
Nas eleições municipais de 2004, ao chegar em Jordânia, um de nós foi surpreendido pela notícia da candidatura da esposa do casal, pela coligação da "família” Santana, na qual nunca votaram. Luiza argumentava que os votos que deram aos agora adversários nunca eram reconhecidos e que, a cada vez que encontravam os chefes políticos da "família" à qual sempre se alinharam, eles tinham que se apresentar novamente, lembrá-los de seus ancestrais comuns e das diversas maneiras como, e quantas vezes eram, parentes. "A sorte é que Funes sabe genealogia”.

No ano anterior, disse ela, o casal encontrou na rua o então prefeito de Jordânia, o principal líder da família política à qual se opunha, os Santana. Esse encontro foi identificado por ela como um ponto de inflexão nas relações entre eles. Espontânea e festivamente, não só os laços de família que os uniam foram lembrados pelo político, mas também, muito importante neste caso, o que os avós de um e de outros realizaram politicamente. Mudança de parentesco, mudança de "política".

Funes sabe genealogia mais que nenhum outro habitante vivo de Jordânia. Celebrizado, seu vasto conhecimento é também avaliado, no entanto, como "sem futuro" ou inútil pela maior parte das pessoas a quem propusemos o tema para reflexão. Saber genealogia vai ao encontro das expectativas locais acerca de o que é ser Jordaniano. Mas não serve realmente para nada. Salvo, claro, e o argumento é nosso, quando essa fonte inesgotável de nomes,

8. Onde fazemos nossa pesquisa, em geral se utiliza o verbo "acompanhar" no lugar de votar. Quando o verbo votar é utilizado, diz-se "votar com" ou "dar seu voto a”, ao invés de "votar em", como dizemos no Sudeste. Essas duas locuções vão ao encontro do argumento de Palmeira (1992), que registrou a mesma observação e para quem os laços entre candidatos e eleitores se estabelecem enquanto adesão, mais do que representação. 
essa 'memória-lembrança', se podemos usar esses conceitos bergsonianos (DELEUZE, 1999), torna-se uma 'memória-contração'. Quer dizer, quando esse saber entra no quadro da ação sofrendo os recortes necessários para funcionar na vida cotidiana.

Se a teoria política de nosso primeiro amigo toma as alianças eleitorais como ponto de partida, recrutando conhecimentos genealógicos precisamente para desqualificá-los como critérios válidos e objetivos para a seleção de candidatos e de candidaturas, Funes, Luiza e seu novo aliado inverteram esse caminho. Eles partiram da genealogia. 0 casal se viu negligenciado política e pessoalmente e se ressentiu pelo tratamento dedicado apenas aos "sem prestígio”, para usar o vocabulário local (VILLELA E MARQUES, 2006), ao passo que a genealogia deveria lhe garantir, como critério seletivo, alguma deferência por parte das lideranças políticas da "família" que há décadas apoiavam. Funes e Luiza não foram considerados "da família”. Nesse caso, apenas os seus votos não foram capazes de adensar o sangue. Por conta, talvez, de basearem-se apenas na genealogia.

Mas foi mesmo a genealogia a responsável pelo novo alinhamento político. Serem reconhecidos como parentes e antigos aliados, dada a habilidade político-genealógica do prefeito Santana, fê-los transpor as fronteiras familiares e partidárias. Talvez essa transposição seja correlata de um processo de reconfiguração familiar e política mais amplo e mais profundo o que se torna possível graças ao fato de todas as antigas famílias serem ligadas entre si por numerosos casamentos celebrados ao longo de séculos, nos quais se originam "ramos" familiares conhecidos e nomeados, particularmente pelos genealogistas mas também, em suas grandes linhas, por todos. Assisti- mos aqui, ao mesmo tempo, a uma familiarização e a uma desfamiliarização; ao sangue adensando a política e vice-versa.

Tudo isso só acontece quando as genealogias estão feitas, desde há muitas décadas, para as famílias antigas e tradicionais. Passaremos a mostrar o que acontece quando a política e a família, em implicação recíproca, propõem-se a fazer uma à outra. 0 que acontece, quais estratégias são criadas ou copiadas, quando um grupo de pessoas, associadas pelo sangue e pela genealogia pretendem constituir-se como família, no duplo sentido da atuação político-eleitoral e do parentesco?

\subsection{Novatos}

Uma nova candidatura a vereador surgiu nas eleições de 2000. Em Jordânia, candidaturas inaugurais, sem base familiar, costumavam, ao menos até recentemente, fadar ao fracasso. Este jovem, a quem chamaremos Ulisses, não pertencia, por genealogia, a nenhuma das famílias importantes do município. Até há um par de gerações, seus parentes estavam circunscritos a uma modesta vila de um outro município, emancipada de Jordânia na década de 1980. As atividades políticas dessa família restringiam-se a "acompanhar" um candidato.

Mas, sabemos já, em Jordânia política faz-se com família. Para ser candidato, é preciso fazer família para que se venha a 'dizer família' (JOLAS et al., 1970). Ao mesmo tempo, para ser uma família de prestígio é necessário fazer política. As estratégias utilizadas para atingir esse objetivo, que passaremos a descrever, reproduzem o modelo transmitido pelas famílias tradicionais, formadas há mais de um século, pelo sangue e pela política eleitoral e familiar.

Assim como as famílias tradicionais, os parentes de Ulisses lançaram mão de recur- 
sos imagéticos e iconográficos. As fotografias entre aquelas famílias são a expressão patente da sua glória passada e da sua consequente influência atual. Nota-se a força de uma família pela qualidade e pela quantidade das fotos dos ancestrais do casal expostas nas paredes da sala, o espaço mais público da casa. Com o aumento do nível socioeconômico e de educação formal das gerações recentes, e com a difusão das tecnologias digitais, começaram a se avolumar as fotos, os vídeos, as árvores genealógicas, os brasões. Se a boa qualidade das velhas fotografias atesta a antiguidade e o prestigio de uma família ou de um "ramo", a quantidade é atualmente a marca das novas formações familiares que pretendem fazer-se "tronco".

Como dissemos anteriormente, o contínuo da genealogia intensiva é recortado politicamente por certos personagens proeminentes a que se podem chamar "troncos". $\mathrm{Na}$ família de Ulisses, camponesa até poucas décadas, não havia personagens desse tipo. Mas ela pôde contar com um homem, ainda vivo, cuja retidão moral, a fé religiosa e o acesso ao mundo supra-humano preencheram as funções de prestígio, fazendo-o passível de se tornar um "tronco". A partir desse homem, puderam-se formular celebrações da família em torno de um ponto de unidade capaz de traçar contornos e pertenças.

Celebração pedagógica e mnemotécnica através da imagem: a iconografia familiar até então dispersa passa a ser exposta na casa de um de seus membros ilustres, o candidato a vereador. Em síntese, a aparição desses dois personagens, o candidato e o “tronco”, liberou a criação de árvores genealógicas. Alguns membros da família exibem, em seu local de trabalho, a versão escrita e diagramada de sua genealogia e a imagem de uma árvore em cujo tronco, ramos e folhas estão inscritos os nomes de seus mem- bros, e que se converte em ícone do grupo da família na rede social Facebook. Celebração, enfım, em sentido literal: uma festa é organizada anualmente para reunir em Jordânia os parentes dispersos nos municípios vizinhos e em outras regiões do país.

A candidatura e a eleição de um parente reforçam o sentimento de parentesco. Elas estimulam a afetividade e as solidariedades, adensam o sangue, incitam a convivialidade e aproximam as pessoas, doravante orgulhosas de fazerem parte dessa família e de portar seu nome. Aí se opera uma contração, ao mesmo tempo deliberada e espontânea, de práticas estendidas no tempo. Trata-se de imitar e sintetizar o que fizeram gerações das famílias tradicionais, depois da ocupação colonial do território, misturando a história política do município às lembranças de família, às descrições genealógicas e às biografias de grandes personagens. Política e família se fazem reciprocamente. 0 número e a coesão dos membros da família crescem e se intensificam a partir desses movimentos que são correlativos ao interesse pela história de seus ancestrais e à capacidade de reencontrar e reconhecer parentes distantes pela via genealógica.

\section{Considerações finais: para além do "san- gue" e da "política"}

Três episódios de crise, três oportunidades de ativar família, não como língua ou idioma, mas como uma realidade ou uma atualização. A família é substancial e material. Ela se exprime pelo sangue, mas se manifesta sobretudo pelas atitudes, pelos gestos, por todo um comportamento. Ela não é, contudo, uma essência, nem um dado natural, nem transcendência. Família precisa ser feita, dita, ensinada, aprendida. Ela exige manutenção constante e mnemo- 
técnica. Ela resulta de táticas e estratégias elaboradas no cotidiano.

Cada habitante do sertão é, ao mesmo tempo, um indivíduo e uma coletividade. Para além de sua trajetória pessoal, tudo que se espera dele ou dela é determinado por uma história longa de várias gerações, por uma quantidade indefinida de biografias, pelo lugar (a casa, a fazenda) de onde vem, pelo "sangue" que corre em suas veias, pelas suas adesões políticas. Através da diversidade de categorias - "tronco", "ramo", "linhagem", "casa" - e dos esquemas de segmentação ativados pelas afiliações políticas ou ilustrados pelas "assinaturas” das orelhas dos bodes, as famílias são o resultado parcial e cambiante de recortes sucessivos de um estoque virtual de parentesco.

Para concluir, a família se presta à reflexão, provoca a curiosidade e suscita dúvidas cada vez que é preciso tomar posição em relação a uma pessoa que não se conhece bem, a fim de familiarizá-la ou desfamiliarizá-la, para além do "sangue" e da "política". Ela opera como um ponto de referência que exprime tanto uma adesão política quanto uma aspiração existencial. Assim, as pessoas são subsumidas nessa socialidade, ao mesmo tempo que a constituem. Todos são objeto de apreciação e curiosidade por parte de quem se interessa pelo parentesco e pela família. "Esse rapaz é do Umbuzeiro? Eles são do povo de Fulano?", questionavam nossos novos conhecidos. A pergunta não é rara, nem reservada aos mais velhos. Ao interrogar sobre seus parentes, os jovens e as crianças localizam-se, da mesma forma que permitem ao interlocutor que os situem quando lhes perguntam "de quem são". Os mais velhos se orgulham quando adivinham qual é a família da pessoa pela observação de seu jeito de andar e de falar, pelas suas expressões e aparência, um saber que logo se aprende a cultivar. "Eu tava olhando o jeito dele andar, o nariz, assim magrinho, pensei que era dos Fulano”. "Não é, não. Ele aqui não tem parente nem aderente”, diziam alguns. "Não, ele é do Rio de Janeiro, mas agora é como um primo nosso, um sobrinho meu", diziam outros, mais queridos e íntimos, a respeito de um de nós, como gostava de insistir a nossa querida amiga D. Ernesta Trindade, a quem este artigo, com muita saudade, é dedicado.

\section{Referências}

ABÉLÈS, M. Avoir du pouvoir politique. In: SEGALEN, M. (Org.). Jeux de familles. Paris: CNRS Éditions. 1991, p. 79-99.

Un anthropologue à l'Assemblé. Paris: Odile Jacob, 2001.

ABREU, C. Caminhos antigos e povoamento do Brasil. Brasília: Ed.UNB, 1982 [1907].

ANDRADE, M. A terra e o homem no Nordeste. São Paulo: Brasiliense, 1986.

ANTONIL, A. Cultura e opulência do Brasil. Belo Horizonte: Itatiaia; São Paulo: Edusp, 1982 [1711].

BEZERRA, M. 0. La politique vue d'en bas. Critique, v. LX 680, n. 1, p. 66-76, 2004.

BOURDIEU, P. La société traditionnelle: attitude à l'égard du temps et conduite économique. Sociologie du Travail , v. 5 n.1, p. 24-44, 1963.

Esquisse d'une théorie de la pratique. Genève: Droz, 1972.

CANDEA, M. Our division of the universe. Current Anthropology, v. 52, n. 3, p. 309-334, 2011.

CARONE, E. A República Velha. São Paulo: Difusão Européia do Livro, 1977.

CARRIER, J. Occidentalism: images of the west. Oxford: Clarenton Press, 1995. 
CARSTEN, J. Cultures of relatedness. Cambridge: Cambridge University Press, 2000.

Blood Will Out. Journal of the Royal Anthropological Institute, v. 19. Special Issue, p. 1-23, 2013.

CARSTEN, J; HUGH-JONES, S. (Orgs.) About the House. Lévi-Strauss and Beyond. Cambridge: Cambridge University Press, 1995.

CARVALHO, J. M. Mandonismo, coronelismo, clientelismo: uma discussão conceitual. Dados, v. 40, n. 2, p. 229-251, 1997.

COMERFORD, J. Como uma família: socialidade, territórios de parentesco e sindicalismo rural. Rio de Janeiro: Relume-Dumará, 2003.

CURTIS, J.; SPENCER J. Anthropology and the Political. In: FARNDON, R.; et al. (Orgs.). Sage Handbook of social Anthropology, v. 1,. London: Sage, 2012, p. 168-182.

DONZELOT, J. La Police des Familles. Paris: Minuit, 1977.

EISENSTADT, S. N.; RONIGER, L. Patrons, Clients and Friends. Cambridge: Cambridge University Press, 1984.

FABIAN, J. Time and the Other. New York: Columbia University Press, 1983.

FERNANDEZ DE LAS HERAS, I. Algo a fazer. Oicogênese e arquitetura no Vale do Araotz (País Basco). Dissertação de Mestrado. PPGAS-UFSCar, 2016.

FOUCAULT, M. Les anormaux. Cours au Collège de France 1974-75. Paris: Gallimard-Seuil, 2001.

La société punitive: Cours au Collège de France 1972-1973. Paris: Gallimard-Seuil, 2013.

GELLNER, E.; WATERBURY, J. Patrons and Clients in Mediterranean Societies. London: Duckworth, 1977.

GOLDMAN, M.; PALMEIRA, M. Apresentação. In: PALMEIRA M; GOLDMAN, M. (Orgs.). Antropologia, voto e representação política. Rio de Janeiro: Contra Capa Livraria, 1996, p. 1-12.
GRAHAM, R. Patronage and Politics in Nineteenth Century Brazil. Stanford: Stanford University Press, 1990.

HERZFELD, M. The Social Production of Indiference. Chicago: Chicago University Press, 1992.

Cultural Intimacy: Social poetics in the Nation-State. New York, London: Routledge, 2005. JOLAS, T.; ZONABEND, F.; VERDIER, Y. Parler famille. L'Homme, v. 10, n. 3, p. 5-26, 1970.

JULLIEN, F. De l'universel, de l'uniforme, du commun et du dialogue entre les cultures. Paris: Fayard, 2008 .

KUPER, A. The Invention of Primitive Society: Transfornation of an Illusion. London: Routledge, 1988 .

LANDÉ, C. The Dyadic Basis of Clientelism. In: SCHMIDT, S.; GUASTI, L.; LANDÉ, e SCOTT, J C. Friends, Followers, and Factions. Berkeley: University of California Press, 1977, p. xiii-xxxvii.

LEAL, V. N. Coronelismo, enxada e voto. Rio de Janeiro: Forense, 1949.

LÉVI-STRAUSS, C. La Voie des Masques. Paris: Plon, 1979 [1972].

LEWIN, L. Politics and Parentela: a Case Study of Familly-based Oligarchy in Brazil. Princeton: Princeton University Press, 1987.

LOIZOS, P. The Greek Gift: politics in a Cypriot Village. Oxford: Basil-Blackwell, 1975.

MARCELIN, L. L'invention de la famille afro-americaine: famille, parenté et domesticité parmi les noires du Recôncavo da Bahia, Brésil. 1996. Tese (Doutorado em Antropologia Social) - Museu National: Universidade Federal de Rio de Janeiro, 1996.

. In the Name of the Nation: Blood Symbolism and the Political Habitus of Violence in Haiti. American Anthropologist, v. 114, n. 2, p. 253-266, 2012.

MARQUES, A. C. Intrigas e questões: vinganças de família e tramas sociais no sertão de Pernambuco. Rio de Janeiro: Relume Dumará, 2002. 
Founders, Ancestors, and Enemies. Journal of the Royal Anthropological Institute, v. 19, p. 716-733, 2013.

MENEZES, D. 0 outro Nordeste. Rio de Janeiro: José Olympio, 1937.

NATHAN, T. Nous ne sommes pas seules au monde. Paris: Les Empêcheurs de Penser en Rond, 2001.

PALMEIRA, M. Voto: racionalidade ou significado? Revista Brasileira de Ciências Sociais, v. 20, p. 26-30, 1992.

PALMEIRA, M.; HEREDIA, B. Le Temps de la Politique. Études Rurales, v. 131-132, n. 1, p.73-87, 1993.

PRADO JR., C. História Econômica do Brasil. São Paulo: Brasiliense, 1980 [1945].

SAMPAIO, P. Sur les traces de Virgolino, un cangaceiro dit "Lampião": fragilités, violences et légalité (Brésil XIXe-XXe siècle). 2000. Tese (Doutorado em Estudos Latino-Americanos) Paris: IHEAL / Université Paris III, 2000.

SANTOS, L. C. Brasil de chapéu de couro. Rio de Janeiro: Civilização Brasileira, 1958.

SCHNEIDER, D. A Critique of the Study of Kinship. Ann Arbor: University of Michigan Press, 1984.

(Original work published 1972) What is Kinship all about? In: PARKIN, R; STONE, L. (Orgs.). Kinship and Familly: an anthropological reader. Malden: Blackwell, 2007, p. 257-274.

SEGALEN, M. Mari et femme dans la société paysanne. Paris: Flammarion, 1981.

Sociologie de la famille. Paris: Armand Collin, 1996.

SPENCER, J. Anthropology, Politics and the State. Cambridge: Cambridge University Press, 2007.

VEYNE, P. Les Grecs ont-ils connu la Démocratie?

Diogène. v. 124, 1983.
VILLELA, J. 0 povo em armas: violência e política no sertão de Pernambuco. Rio de Janeiro: Relume Dumará, 2004.

. 0 dinheiro e suas diversas faces nas eleições do sertão de Pernambuco. Mana, v. 1, n. 1, p. 267-296, 2005

. Política e eleições no sertão de Pernambuco. Campinas: Pontes, 2008.

VILLELA, J.; MARQUES. A. C. Municipal Elections: favor, vote and credit in the Pernambucan Sertão of Brazil. Latin Americanist, v. 49, n. 2, p. 25-63, 2006.

WOLF, E. Kinship, Friendship, and Patron-client Relations in Complex Society. In: BANTON, M. (Org.). The Social Anthropology of Complex Society. London: Tavistock, 1966, p. 1-20. 
RESUMO

Um dos objetivos aclamados da democracia é a purificação do governo em relação aos interesses familiares, embora esse ideal não seja alcançado em parte alguma. Com base em etnografia realizada em um município do sertão de Pernambuco, neste artigo mostramos como em certas circunstâncias família e política são sinônimos e, de forma mais geral, como parentesco e política não são concebidos como domínios autônomos. A partir da discussão concernente a categorias locais de família, três circunstâncias de crise são identificadas, de modo a demonstrar a inextricável articulação entre sangue e política.

\section{PALAVRAS-CHAVE}

Política. Eleições. Parentesco. Família. Sangue. Sertão de Pernambuco.

\section{ABSTRACT}

Despite the seeming impossibility of attaining a pure form of democracy, one of democracy's cherished aims is to purify the realm of governance from family interests. In this article, which is based on ethnography collected in a municipality located in Pernambuco, Northeast Brazil, we reflect on the manner in which notions of family and politics become at once synonymous in some circunstances. In this context, we suggest, politics and kinship cannot be conceptualised as autonomous domains. Through an exploration of family categories, we identify three circumstances of crisis in which blood and politics are inextricably linked.

\section{KEYWORDS}

Politics. Elections. Kinship. Family. Blood. Hinterlands of Pernambuco. 